J Pharm Pharm Sci (www.cspsCanada.org) 21(1s), 130s - 148s, 2018

\title{
Understanding the Monoclonal Antibody Disposition after Subcutaneous Administration using a Minimal Physiologically based Pharmacokinetic Model
}

\author{
Ninad Varkhede, M. Laird Forrest \\ Department of Pharmaceutical Chemistry, The University of Kansas, Lawrence, Kansas 66047, USA.
}

Received, June 18, 2018; Accepted, July 13, 2018; Published, July 14, 2018.

\begin{abstract}
Purpose: Monoclonal antibodies (mAbs) are commonly administered via subcutaneous (SC) route. However, bioavailability is often reduced after SC administration. In addition, the sequential transfer of $\mathrm{mAbs}$ through the SC tissue and lymphatic system is not completely understood. Therefore, major objectives of this study were a) To understand absorption of mAbs via the lymphatic system after SC administration using physiologically based pharmacokinetic (PBPK) modeling, and $b$ ) to demonstrate application of the model for prediction of SC pharmacokinetics (PK) of mAbs. Methods: A minimal PBPK model was constructed using various physiological parameters related to the SC injection site and lymphatic system. The remainder of the body organs were represented using a 2-compartment model (central and peripheral compartments), with parameters derived from available intravenous (IV) PK data. The IV and SC clinical PK data of a total of $10 \mathrm{mAbs}$ were obtained from literature. The SC PK data were used to estimate the lymphatic trunk-lymph node (LN) clearance. Results: The mean estimated lymphatic trunk-LN clearance obtained from 37 SC PK profiles of mAbs was $0.00213 \mathrm{~L} / \mathrm{h}(0.001332$ to $0.002928,95 \%$ confidence intervals). The estimated lymphatic trunk-LN clearance was greater for the $\mathrm{mAbs}$ with higher isoelectric point $(p I)$. In addition, the estimated clearance increased with decrease in the bioavailability. Conclusion: The minimal PBPK model identified SC injection site lymph flow, afferent and efferent lymph flows, and volumes associated with the SC injection site, lymphatic capillaries and lymphatic trunk-LN as important physiological parameters governing the absorption of $\mathrm{mAbs}$ after $\mathrm{SC}$ administration. The model may be used to predict PK of mAbs using the relationship of lymphatic trunk-LN clearance and the $p I$. In addition, the model can be used as a bottom platform to incorporate $\mathrm{SC}$ and lymphatic in vitro clearance data for $\mathrm{mAb} \mathrm{PK}$ prediction in the future.
\end{abstract}

\section{INTRODUCTION}

Monoclonal antibodies (mAbs) are an important class of therapeutic proteins (TPs) administered mainly via subcutaneous (SC) route due to shorter clinical visits for patients, the possibility of selfadministration, and its less invasive nature. However, when compared to the intravenous (IV) route, SC injection has challenges associated with the incomplete bioavailability and pain-free administration of larger fluid volumes (1). The SC tissue and lymphatic system are important barriers for the absorption of mAbs. After SC administration, the mAbs travel through the lymphatic vessels and lymph nodes before reaching the systemic circulation. The SC bioavailability of mAbs is typically in the range of 52 to $80 \%(2,3)$. Proteolysis within the lymphatic system and the SC injection site may be partially responsible for the reduced bioavailability of mAbs. The rate of neonatal Fc receptor $(\mathrm{FcRn})$ binding and recycling exceeds the rate of lysosomal/endosomal trafficking of mAbs; therefore, endosomal proteolysis may contribute only minimally to low mAb bioavailability $(3,4)$. In addition, the target mediated drug disposition (TMDD) is often saturated due to limited receptors. Thus, mAbs are cleared slowly from the systemic circulation. The TPs like IgG1, IgG2 and IgG4 have a long half-life of around 23 days (3), which is substantially longer than other proteins of similar molecular weights. Further, the appearance rate of mAbs in the plasma is slow ( $T_{\max }$ generally 2-14 days) (3). The low bioavailability of mAbs may result from efficient pre-systemic clearance mechanisms or irreversible retention (and subsequent elimination) of significant dose at the injection site or in the surrounding tissues.

Corresponding Author: M. Laird Forrest, 2095 Constant Ave Lawrence, KS 66047; Telephone: 785-864-4388; e-mail: 1forrest@ku.edu 
Charman et al. investigated the causes of reduced bioavailability of human growth hormone (hGH) protein using a sheep model. The SC injection site degradation was minimal for $\mathrm{hGH}$, while the lymphatic proteolysis was mainly responsible for its reduced bioavailability after SC administration (5). We hypothesize that the interstitial proteolysis in the lymphatic system may be responsible for lower bioavailability of mAbs after SC administration. In this study, a minimal physiologically based pharmacokinetic (PBPK) model was used to understand the sequential transit of $\mathrm{mAbs}$ and to estimate lymphatic clearance using the SC pharmacokinetics (PK). The model was constructed using physiological parameters related to the SC injection site, lymphatic system and the reported clinical IV PK data. This study had the following major objectives: a) construction of the minimal PBPK model focusing on the lymphatic transit of $\mathrm{mAbs}$ after SC administration using physiologically relevant lymph flows and compartment volumes, b) estimation of the lymphatic clearance using literature SC PK data, and c) identification of the parameters governing the absorption of mAbs via the $\mathrm{SC}$ and lymphatic system.

Various PBPK models for TPs have been reported recently and as early as 1995 (Gill et al., Abbuqayyas and Balthasar, Garg and Balthasar, Baxter et al., Shah and Betts) (6-9). Some of the authors (Zhao et al., Chen et al., Elmeliegy et al., Li et al.) proposed the minimal PBPK approach to eliminate complexity associated with the models (3, 10-12). Although, these models may be useful for a mechanistic understanding of the clearance and absorption processes at the SC injection site and in the lymphatic system, use of PBPK modeling for TP PK prediction is limited (13). After SC injection, the $\mathrm{mAb}$ travels through the lymphatic capillary network, lymph nodes, lymphatic trunks and thoracic lymph duct before joining the systemic circulation. Hence, in this study, the lymphatic organs were incorporated in the minimal PBPK model, and the lymphatic trunk-lymph node (LN) clearance was estimated using the SC PK. Interestingly, it appears that the estimated lymphatic trunk-LN clearance was directly proportional to the isoelectric point $(p I)$ of the $\mathrm{mAb}$. In addition, the model must be combined in the future with in vitro proteolysis data obtained from the lymphatic system to predict SC PK and bioavailability of mAbs. Further, the variability in the PK due to different populations, disease conditions, formulations, novel delivery technologies, and biophysical properties of the TP may be addressed using the minimal PBPK model (14). Overall, the proposed minimal PBPK model can be used for mechanistic understanding of $\mathrm{mAb}$ absorption and prediction of PKPK after SC administration.

\section{METHODS}

\section{Digitization of literature IV and SC PK data}

The IV ( 35 profiles) and SC ( 37 profiles) PK of 10 $\mathrm{mAbs}$ were obtained from literature and digitized using WebPlotDigitizer (version 4.1) (15). This webbased tool has been extensively used in other reports (16). The IV PK profiles were used to estimate 2compartment model parameters, while the SC PK profiles were used to estimate the lymphatic trunkLN clearance.

\section{Construction of the minimal PBPK model}

The minimal PBPK model was constructed using SimBiology (Matlab R2017a). The physiologically based model and simple compartmental model were combined to describe absorption of mAbs after SC administration (Figure 1). The model equations describing FcRn binding and transfer across interstitial, endosomal and vascular space were adopted from previously reported studies $(3,9,17)$. However, additional physiological parameters related to the lymphatic system were either calculated or obtained from the literature (Table 1) and used to construct the model. The model parameters specific to mAbs are listed in Table 2. Furthermore, additional compartments were included to describe the sequential transfer of mAbs through the lymphatic system. It was assumed that the SC dose of $\mathrm{mAb}$ distributes equally in the SC interstitial space after the injection.

\section{Physiological parameters related to the SC injection site and lymphatic system}

The physiological parameters related to the SC injection site and lymphatic system were either obtained or calculated from the literature (Table 1). The SC injection site volume was calculated by Gill et al. (9) using the diameter of the SC injection depot of radiolabeled IgG. While, the SC site lymph flow was measured using the rate of radiolabeled IgG loss from a SC administration site (9). Lymphatic capillary volume was calculated using the average distance between the injection site and sentinel LN $(30 \mathrm{~cm})$, the lymphatic network density per $1 \mathrm{~cm}$ 
annulus of arm skin $(385 \mathrm{~cm})$, and the average radius of lymphatic capillaries $(0.0274 \mathrm{~mm})(18-20)$. Afferent lymph flow was calculated using the reported lymphatic flow rate $(40 \mathrm{~mm} / \mathrm{min})$ and radius $(0.0274 \mathrm{~mm})$ of the lymphatic capillaries in humans $(21,22)$. The efferent lymph flow rate in sheep was used in the model (23). The volume of the lymphatic trunk was calculated based on an approximate length of $30 \mathrm{~cm}$ and a radius of $1 \mathrm{~mm}(20)$. The total LN volume was calculated based on the number of LNs (45 to 50) to which which the mAb is exposed after $\mathrm{SC}$ injection in thigh (24-26). The average volume of cervical LNs $(0.292 \mathrm{~mL})$ reported in humans was used to calculate the total LN volume after SC injection in the upper arm, abdomen, and thigh (27). The SC injection of a TP in thigh would lead to its travel through the inguinal, iliac and lumbar LNs (Figure 2). Upon SC injection in the upper arm, the TP would travel through the cubital and axillary LNs followed by the subclavian trunk. After passing through the LNs and lymphatic trunks, TPs would join the central lymphatic system (thoracic duct and cysterna chyli), which are lymphatic vessels with greater diameters.

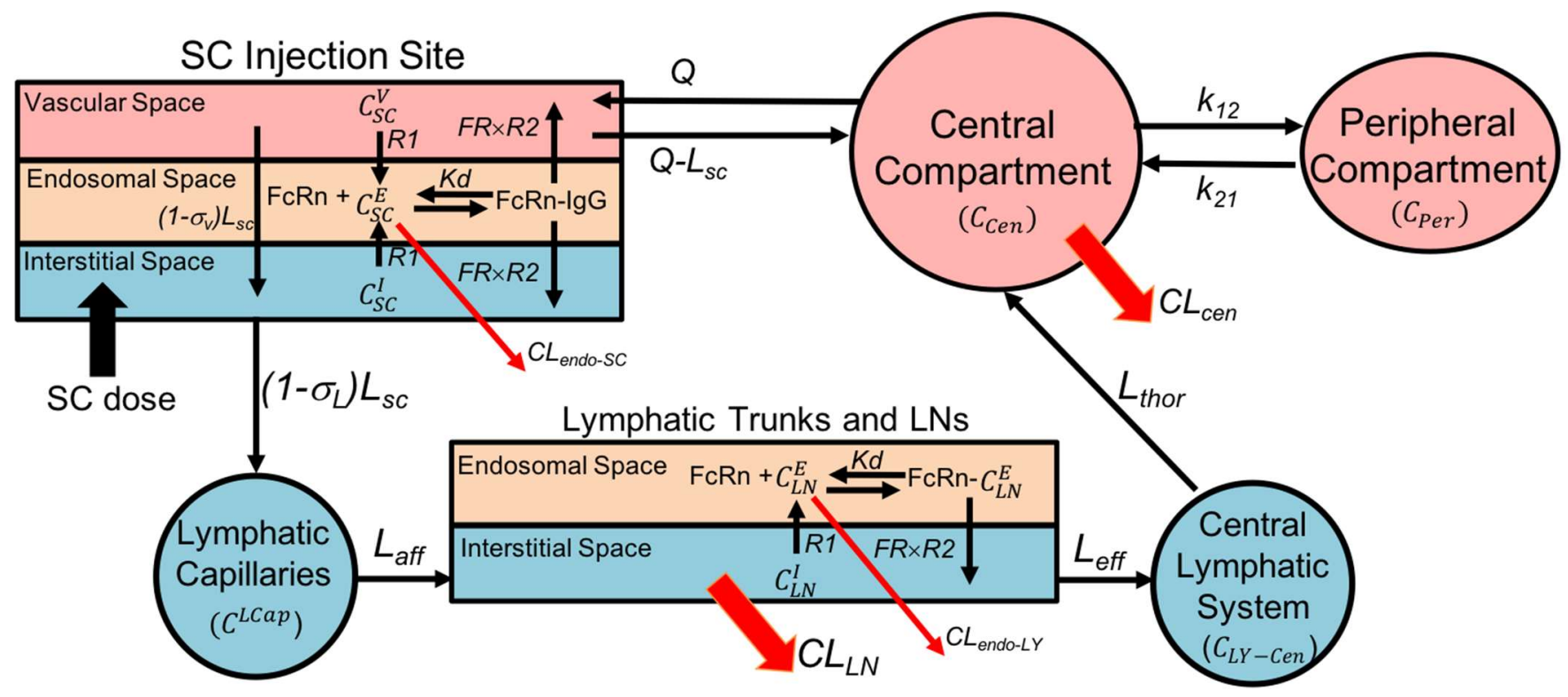

Figure 1. Schematic of the minimal PBPK model for mAb absorption after SC injection

Towards systemic circulation
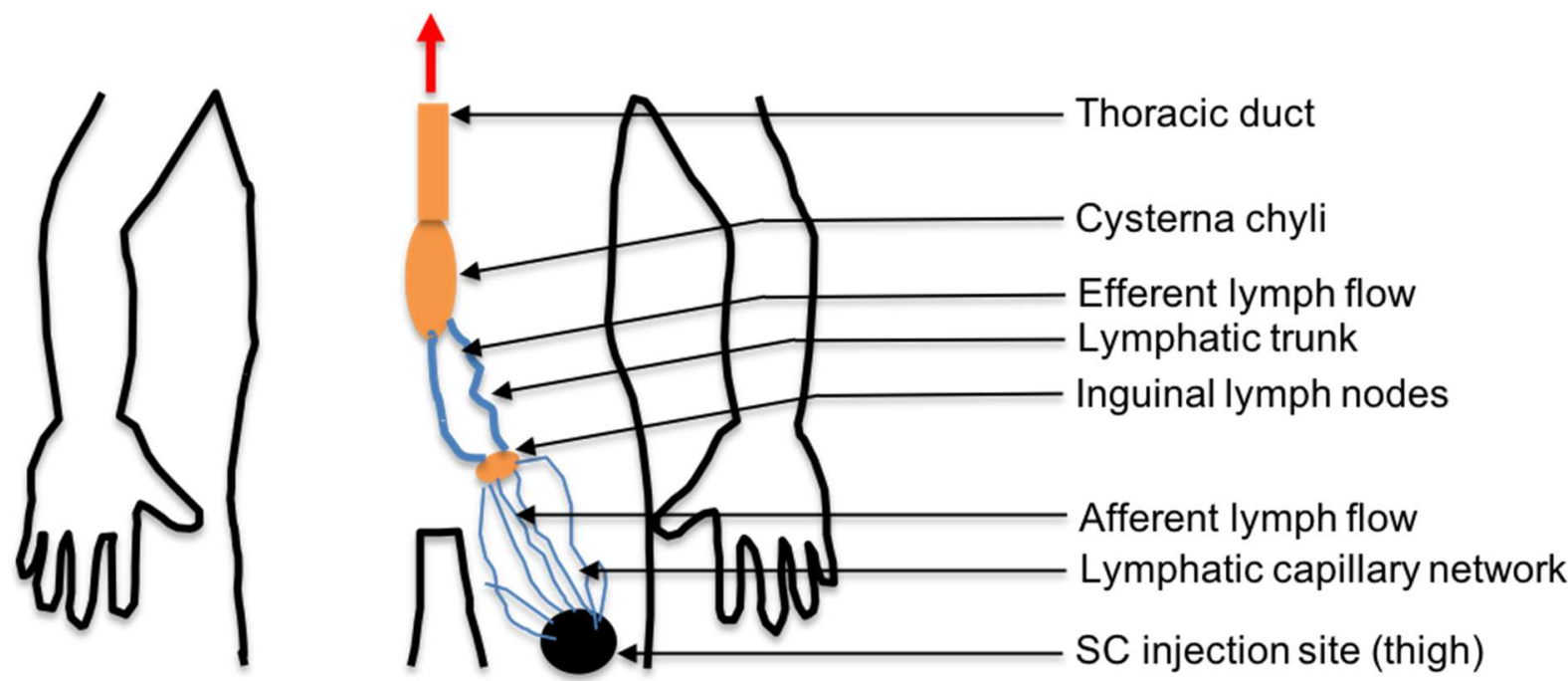

Figure 2. Schematic representation of flow of mAbs or TPs after SC injection in thigh 
The TP would join the systemic circulation via the thoracic duct if the SC injection site were left upper arm, whereas injections into the right upper arm, would enter either via the right thoracic duct or thoracic lymph duct (Figure 3). After abdominal SC injection, the TP would generally travel via inguinal, iliac, and lumbar LNs towards the cisterna chyli and thoracic duct, to enter the systemic blood circulation via the subclavian vein. The known anatomical structure of lymphatic system was utilized to define the sequential transfer of mAbs (24-27).

The lymphatic trunk and LN volumes were combined to calculate the interstitial lymphatic trunk-LN volume. The total endosomal volume of LNs was calculated based on the endosomal volume in a peripheral mononuclear cell (28) and the number of lymphocytes in a LN (29). The endosomal LN volume and the combined lymphatic trunk-LN interstitial volume for various SC injection sites (thigh, abdomen, and upper arm) were approximately similar (Table 1).

The central lymphatic system's volume was dependent on the site of SC injection. In the case of $\mathrm{SC}$ injection to the thigh, abdomen or left upper arm, the TP would travel through the thoracic lymph duct. In the case of thigh and abdominal injections, volume of the cisterna chyli should be included in the central lymphatic volume. For this model, it was assumed that the SC injection site was either thigh or abdomen, therefore, the volume of the thoracic duct and cisterna chyli were included in the central

A) Thigh

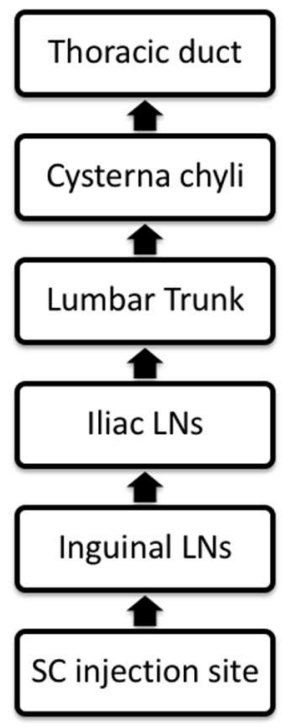

B) Abdomen

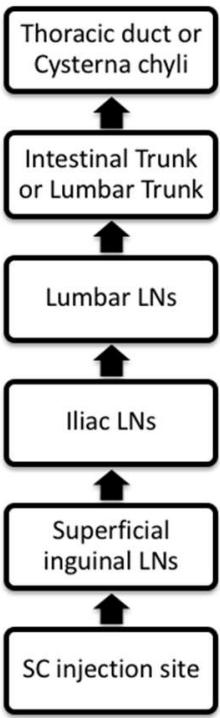

lymphatic volume. However, the volume of the central lymphatic system after injection in an upper arm or thigh was found to be similar, because the volume of the cisterna chyli was negligible as compared to the thoracic duct volume (Table 1). Volumes of the thoracic lymph duct and cisterna chyli were calculated based on literature values of length and diameter. In the case of the thoracic lymph duct, the length and diameter were 45 and 5 $\mathrm{cm}$, respectively. While, in the case of cisterna chyli, the length and diameter were $2-5 \mathrm{~mm}$ and $1 \mathrm{~cm}$, respectively (30).

\section{Parameter estimation and sensitivity analysis}

A nonlinear mixed-effects model with stochastic EM algorithm was used for estimation of the 2compatmental IV PK parameters. The lymphatic trunk-LN clearance was estimated using either the nonlinear mixed-effects model with stochastic EM algorithm or a nonlinear least squares solver. Sensitivity analysis was performed on the physiological, $\mathrm{mAb}$ related and estimated parameters (Supplementary Figure 1 and 2). The parameters were altered by 0.1-, 0.3-, 0.5-, 0.7-, 1-, $3-, 5-, 7-, 10-, 50-$ and 100-fold of the original values as mentioned in Table 1. The lymphatic reflection coefficient was altered by $0.1-, 0.3-, 0.5-, 0.7-, 1-$, 1.5-, 2-, 2.5-, 3-, 3.5-, 4-, 4.5-, 5- folds of the original parameter value and its impact on the PK of mAbs was determined.

Figure 3. Sequential transfer of mAbs towards the systemic circulation after SC injection in, A) Thigh, B) Abdomen, and C) Upper Arm. 
Table 1. Human physiological parameters related to the SC injection site and lymphatic system

\begin{tabular}{|c|c|c|}
\hline Parameter & Value & Reference \\
\hline$V_{S C}^{I}(\mathrm{SC}$ injection site interstitial volume) & $0.003115 \mathrm{~L}$ & (9) \\
\hline$V_{S C}^{E}(\mathrm{SC}$ injection site endosomal volume $)$ & $0.000025 \mathrm{~L}$ & (9) \\
\hline$V_{S C}^{V}(\mathrm{SC}$ injection site vascular volume $)$ & $0.00025 \mathrm{~L}$ & (9) \\
\hline$V^{\text {LCap }}$ (Volume of the lymphatic capillaries) & $0.00033 \mathrm{~L}$ & Calculated (18-20) \\
\hline $\begin{array}{l}V_{L Y-U A}^{I}(\text { Combined interstitial volume of lymphatic trunk } \\
\text { and LNs after SC injection in upper arm) })^{\mathrm{a}}\end{array}$ & $0.01408 \mathrm{~L}$ & Calculated (24-27) \\
\hline $\begin{array}{l}V_{L Y}^{I} \text { (Combined interstitial volume of lymphatic trunk and } \\
\text { LNs after SC injection in thigh) }\end{array}$ & $0.01349 \mathrm{~L}$ & $\begin{array}{l}\text { Calculated }(25-27, \\
31)\end{array}$ \\
\hline $\begin{array}{l}V_{L Y-A b}^{I} \text { (Combined interstitial volume of lymphatic trunk } \\
\text { and LNs after SC injection in abdomen) }\end{array}$ & $0.01758 \mathrm{~L}$ & $\begin{array}{l}\text { Calculated }(25-27, \\
32)\end{array}$ \\
\hline 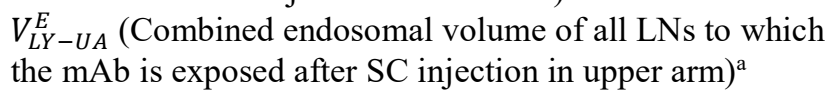 & $0.000014 \mathrm{~mL}$ & Calculated (24-29) \\
\hline $\begin{array}{l}V_{L Y}^{E} \text { (Combined endosomal volume of all LNs to which the } \\
\mathrm{mAb} \text { is exposed after SC injection in thigh) }\end{array}$ & $0.0000126 \mathrm{~mL}$ & $\begin{array}{l}\text { Calculated }(28,29 \text {, } \\
31)\end{array}$ \\
\hline $\begin{array}{l}V_{L Y-A b}^{E} \text { (Combined endosomal volume of all } \mathrm{LNs} \text { to which } \\
\text { the } \mathrm{mAb} \text { is exposed after } \mathrm{SC} \text { injection in abdomen) }\end{array}$ & $0.00001596 \mathrm{~mL}$ & $\begin{array}{l}\text { Calculated }(25-29 \text {, } \\
\text { 32) }\end{array}$ \\
\hline$V_{L Y-C e n}($ Volume of central lymphatic system) & $0.00888 \mathrm{~L}$ & Calculated (30) \\
\hline$V_{\text {Thor }}$ (Volume of thoracic lymph duct) $^{\mathrm{b}}$ & $0.00884 \mathrm{~L}$ & Calculated (30) \\
\hline$V_{C C}(\text { Volume of cisterna chyli })^{\mathrm{b}}$ & $0.000039 \mathrm{~L}$ & Calculated (30) \\
\hline$L_{S C}$ (Lymph flow at the SC injection site) & $0.0001356 \mathrm{~L} / \mathrm{h}$ & $(9)$ \\
\hline$L_{A f f}$ (Lymph flow afferent to LNs in human) & $0.00000564 \mathrm{~L} / \mathrm{h}$ & Calculated $(21,22)$ \\
\hline$L_{E f f}($ Lymph flow efferent to LNs in sheep) & $0.00387 \mathrm{~L} / \mathrm{h}$ & (23) \\
\hline$L_{\text {Thor }}$ (Thoracic duct lymph flow rate) & $0.06 \mathrm{~L} / \mathrm{h}$ & $(33,34)$ \\
\hline$Q_{S C}($ Blood flow at the SC injection site) & $0.04992 \mathrm{~L} / \mathrm{h}$ & (9) \\
\hline $\begin{array}{l}C_{\text {Endo }} \text { (Concentration of endogenous } \mathrm{mAb} \text { in endosomal } \\
\text { compartment) }\end{array}$ & $10000 \mathrm{mg} / \mathrm{L}$ & (3) \\
\hline$K d$ (Dissociation constant for antibody FcRn binding) & $45.36 \mathrm{mg} / \mathrm{L}$ & (35) \\
\hline$n P t$ (FcRn concentration in $\mathrm{SC}$ tissue or $\mathrm{LNs})$ & $2880 \mathrm{mg} / \mathrm{L}$ & (36) \\
\hline
\end{tabular}

Table 2. mAb related parameters used in the minimal PBPK model

\begin{tabular}{lll}
\hline Parameter & Value & Reference \\
\hline$\sigma_{V}$ (Vascular reflection coefficient) & 0.95 & $(3,17)$ \\
$\sigma_{L}$ (Lymphatic reflection coefficient) & 0.2 & $(3,17)$ \\
$R 1$ (Endosomal uptake rate of antibody) & $0.00000926 / \mathrm{h}$ & $(3,4)$ \\
$R 2$ (Endosomal return rate of antibody) & $0.26 / \mathrm{h}$ & $(3,4)$ \\
$F R$ (Recycling fraction of FcRn bound mAb) & 0.715 & $(3)$ \\
$C L_{\text {Endo-SC }}$ (Endosomal clearance of mAb in SC injection site) ${ }^{\mathrm{a}}$ & $0.003675 \mathrm{~L} / \mathrm{h}$ & $(17)$ \\
$C L_{\text {Endo-LY }}$ (Endosomal clearance of antibody in LNs) ${ }^{\mathrm{b}}$ & $0.0001254 \mathrm{~L} / \mathrm{h}$ & $(17)$ \\
\hline${ }^{a}$ Endosomal clearance in skin assumed to be similar to SC injection site & \\
${ }^{b}$ Endosomal clearance in spleen assumed to be similar to lymphatic trunk-LN & \\
\hline
\end{tabular}

\section{Model validation}

The model was validated by comparing observed and predicted PK profiles after SC administration. In addition, accuracy of the predictions was assessed by plotting ratios of $T_{\max \text {-observed }} / T_{\max -\text { predicted, }}, C_{\max -}$ observed $/ C_{\text {max-predicted }}$ with the $p I$, lymphatic trunk-LN clearance, and bioavailability (Supplementary Figure 3, 4 and 5). The bioavailability and $p I$ values for $\mathrm{mAbs}$ were obtained from the literature (37-50). In the case of anifrolumab, the $p I$ value was 
estimated using the amino acid sequence (51) and ProtParam, a web-based tool (52).

\section{RESULTS}

\section{Estimation of the 2-compartment IV parameters}

The 2-compartment model was used to estimate the parameters using the literature PK data after IV bolus or infusion (Table 3). These parameters were different for each $\mathrm{mAb}$, and they were fixed in the minimal PBPK model. The mAbs had average volume of $3.5571 \mathrm{~L}$ (standard deviation, \pm 1.1081 ) for the central compartment and $1.8069 \mathrm{~L}$ (standard deviation, \pm 1.0308 ) for the peripheral compartment. Mean values for $C L_{c e n}, K_{12}$ and $K_{2 l}$ were $0.01531 \mathrm{~L} / \mathrm{h}$, $0.0992 / \mathrm{h}$ and $0.3448 / \mathrm{h}$, respectively.
Estimation of the lymphatic trunk-LN clearance A single parameter (lymphatic trunk-LN clearance) was estimated and the rest of the model was fixed using literature values as described in the methods section. The clearance represents proteolysis of $\mathrm{mAbs}$ in the interstitial space of the lymphatic trunks and LNs (Figure 4). The model predicted a total of 37 SC PK profiles (10 mAbs with 26 different doses), which were compared with the mean observed published data (Figure 5 and 6). However, in the case of belimumab, the patient-PK profile was a geometric mean. The estimated lymphatic trunkLN clearance was in the range of 0.0001495 to $0.007776 \mathrm{~L} / \mathrm{h}$ with a mean of $0.00213 \mathrm{~L} / \mathrm{h}(0.001332$ to 0.002928 , lower and upper $95 \%$ confidence intervals of the mean) for a total of $37 \mathrm{SC}$ PK profiles. Average lymphatic trunk-LN clearance values for each $\mathrm{mAb}$ are shown in Table 4 .

Table 3. The 2-compartmental model parameters for various mAbs after IV administration

\begin{tabular}{|c|c|c|c|c|c|c|}
\hline $\mathbf{m A b}$ & $V_{c e n}(\mathrm{~L})$ & $V_{p e r}(\mathrm{~L})$ & $C L_{c e n}(\mathrm{~L} / \mathrm{h})$ & $K_{12}(/ \mathrm{h})$ & $K_{21}(/ \mathbf{h})$ & Reference \\
\hline Adalimumab & 3.2131 & 2.2382 & 0.01023 & 0.01162 & 0.01669 & $(53)$ \\
\hline Anifrolumab & 2.1732 & 3.7869 & 0.0111 & 0.02024 & 0.01161 & $(54)$ \\
\hline Belimumab & 3.0486 & 2.3877 & 0.009602 & 0.01635 & 0.0208 & $(43,44)$ \\
\hline Canakinumab & 3.2897 & 2.3638 & 0.007541 & 0.009417 & 0.0131 & (40) \\
\hline Daclizumab & 5.5255 & 1.762 & 0.01104 & 0.00257 & 0.00805 & $(55)$ \\
\hline Golimumab & 2.3293 & 2.3279 & 0.01467 & 0.01302 & 0.01302 & $(42,56)$ \\
\hline Guselkumab & 4.9381 & 0.4131 & 0.0233 & 0.000871 & 0.0104 & (46) \\
\hline Infliximab & 4.5782 & 1.2645 & 0.0169 & 0.8914 & 3.2276 & (57) \\
\hline Tocilizumab & 3.5145 & 1.0064 & 0.03585 & 0.01084 & 0.0378 & $(58)$ \\
\hline Trastuzumab & 2.9608 & 0.5186 & 0.01291 & 0.0157 & 0.0896 & $(59,60)$ \\
\hline Mean & 3.5571 & 1.8069 & 0.01531 & 0.0992 & 0.3448 & \\
\hline Standard deviation & 1.1081 & 1.0308 & 0.00849 & 0.2784 & 1.0131 & \\
\hline
\end{tabular}

a) Lymphatic Trunk-LN Clearance

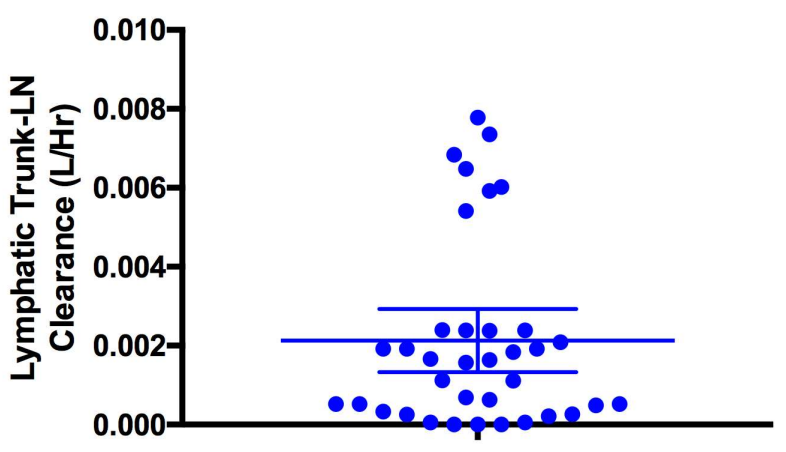

Monoclonal Antibodies b) Lymphatic Trunk-LN Clearance

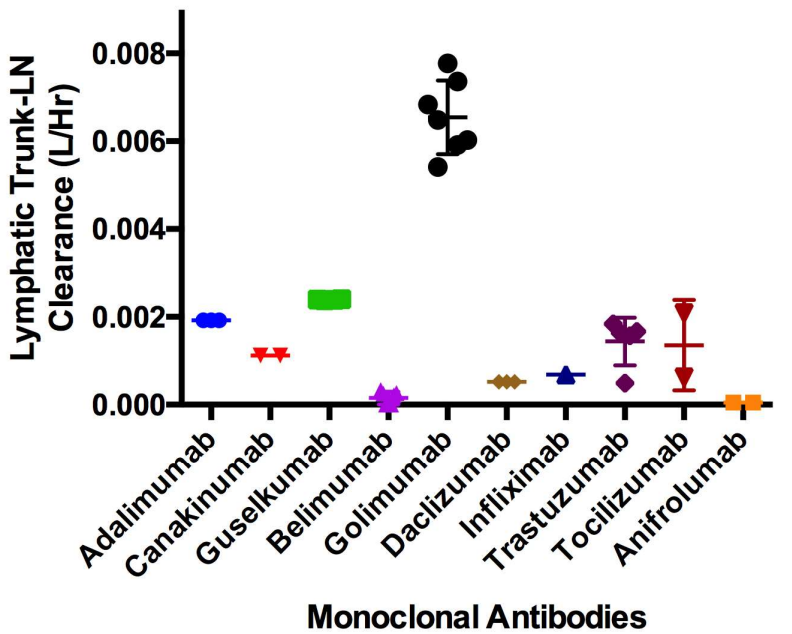

Figure 4. Estimated lymphatic trunk-LN clearance for a) all mAbs used in this study, b) individual mAbs (Mean with $95 \%$ confidence interval) 
J Pharm Pharm Sci (www.cspsCanada.org) 21(1s), 130s - 148s, 2018

Table 4. Estimation of lymphatic trunk-LN clearance after SC administration of mAbs

\begin{tabular}{|c|c|c|c|c|}
\hline mAb (SC injection site) & SC Dose and (F) & Population & Ref. & $\begin{array}{c}\text { Model estimated } \\
\text { average } C L_{L N}\end{array}$ \\
\hline $\begin{array}{l}\text { Adalimumab (Lower } \\
\text { abdomen) }\end{array}$ & $40 \mathrm{mg}(64 \%)$ & Healthy volunteers & (39) & $0.00192 \mathrm{~L} / \mathrm{h}$ \\
\hline Anifrolumab (Abdomen) & $300,600 \mathrm{mg}(73 \%)$ & Healthy volunteers & (45) & $0.00005105 \mathrm{~L} / \mathrm{h}$ \\
\hline $\begin{array}{c}\text { Belimumab* (Abdomen or } \\
\text { thigh) }\end{array}$ & $\begin{array}{c}200,2 * 120,240 \mathrm{mg} \\
(76 \%)\end{array}$ & $\begin{array}{l}\text { Lupus erythromatosus } \\
\text { patients }\end{array}$ & (43) & $0.0002564 \mathrm{~L} / \mathrm{h}$ \\
\hline $\begin{array}{c}\text { Belimumab (Abdomen or } \\
\text { thigh) }\end{array}$ & $\begin{array}{c}200,2 * 120,240 \mathrm{mg} \\
(76 \%)\end{array}$ & Healthy volunteers & (44) & $0.00000024 \mathrm{~L} / \mathrm{h}$ \\
\hline Canakinumab (NA) & $150,300 \mathrm{mg}(70 \%)$ & Healthy volunteers & (40) & $0.001116 \mathrm{~L} / \mathrm{h}$ \\
\hline $\begin{array}{c}\text { Daclizumab** (NA) } \\
\text { Golimumab }\end{array}$ & $50,150,300 \mathrm{mg}$ & Healthy volunteers & $(55)$ & $0.0005207 \mathrm{~L} / \mathrm{h}$ \\
\hline $\begin{array}{c}\text { (Abdomen/Thigh/Upper } \\
\text { Arm) }\end{array}$ & $50,100 \mathrm{mg}(50 \%)$ & Healthy volunteers & $(41,42)$ & $0.00651 \mathrm{~L} / \mathrm{h}$ \\
\hline Guselkumab (NA) & $\begin{array}{c}10,30,100,300 \mathrm{mg} \\
(49 \%)\end{array}$ & Healthy volunteers & $(46,47)$ & $0.002389 \mathrm{~L} / \mathrm{h}$ \\
\hline Infliximab (NA) & $\begin{array}{c}100 \mathrm{mg} \text { (on day } 0,28 \\
\text { and 56) }(71 \%)\end{array}$ & $\begin{array}{l}\text { Rheumatoid arthritis } \\
\text { patients }\end{array}$ & $(61,62)$ & $0.0006855 \mathrm{~L} / \mathrm{h}^{\mathrm{a}}$ \\
\hline Tocilizumab (Abdomen) & $162 \mathrm{mg}(49 \%)$ & Healthy volunteers & (58) & $0.002085 \mathrm{~L} / \mathrm{h}^{\mathrm{a}}$ \\
\hline Tocilizumab (Thigh) & $\begin{array}{c}162 \mathrm{mg} \text { (with } \\
\text { hyaluronidase) }\end{array}$ & Healthy volunteers & (63) & $0.0006258 \mathrm{~L} / \mathrm{h}^{\mathrm{a}, \mathrm{b}}$ \\
\hline Trastuzumab (Thigh) & $\begin{array}{l}482,645 \text {, and } 776 \mathrm{mg} \\
\text { (with hyaluronidase) }\end{array}$ & Healthy volunteers & (64) & $0.001621 \mathrm{~L} / \mathrm{h}^{\mathrm{a}, \mathrm{c}}$ \\
\hline Trastuzumab (Thigh) & $\begin{array}{c}895 \mathrm{mg} \text { (with } \\
\text { hyaluronidase) }\end{array}$ & $\begin{array}{l}\text { HER2-positive breast } \\
\text { cancer patients }\end{array}$ & (64) & $0.0004889 \mathrm{~L} / \mathrm{h}^{\mathrm{a}, \mathrm{d}}$ \\
\hline Trastuzumab (Thigh) & $\begin{array}{c}600 \mathrm{mg} \text { (with } \\
\text { hyaluronidase) }\end{array}$ & Healthy volunteers & (65) & $0.001839 \mathrm{~L} / \mathrm{h}^{\mathrm{a}, \mathrm{e}}$ \\
\hline
\end{tabular}

Mean $C L_{L N}: 0.00213 \mathrm{~L} / \mathrm{h}$ (Standard deviation: 0.002359 , lower $95 \%$ confidence interval of the mean: 0.001332, upper $95 \%$ confidence interval of the mean: $0.002928 \mathrm{~L} / \mathrm{h}$ )

Nonlinear mixed-effects model with stochastic EM algorithm used for estimation of the parameters unless indicated. All observed SC PK data were mean values unless indicated.

${ }^{\mathrm{a}}$ Nonlinear least squares solver

${ }^{b} S C$ Site lymph flow $(0.04474 \mathrm{~L} / \mathrm{h})$ and $C L_{L N}$ estimated simultaneously

'SC Site lymph flow $(0.002798 \mathrm{~L} / \mathrm{h})$ and $C L_{L N}$ estimated simultaneously

dSC Site lymph flow $(0.003112 \mathrm{~L} / \mathrm{h})$ and $C L_{L N}$ estimated simultaneously

eSC Site lymph flow $(0.01307 \mathrm{~L} / \mathrm{h})$ and $C L_{L N}$ estimated simultaneously

F: Bioavailability after SC administration

${ }^{*}$ Geometric mean of the observed pharmacokinetic data

**The model simulated median pharmacokinetic data

$C L_{L N}$ : Clearance of $\mathrm{mAb}$ in the lymphatic trunk-LN interstitial compartment

NA: Not available

\section{Applications of the minimal PBPK model to evaluate impact of hyaluronidase in the $\mathrm{mAb}$ formulation}

The mAbs for the SC administration are formulated as highly concentrated solutions in order to deliver higher doses (typically 500-900 mg). The injection volume cannot be increased more than $1-2 \mathrm{~mL}$ due to injection discomfort (66). However, hyaluronidase has been used in several studies to allow higher injection volumes by disrupting the complex network of the SC extracellular matrix formed by hyaluronic acid. In addition, the hyaluronidase enzyme can increase the rate of TP absorption leading to decreased $T_{\max }$, increased $C_{\max }$, increased area under the curve (AUC), and enhanced bioavailability of the TPs $(66,67)$. In this study, the SC PK data obtained after co-formulation of hyaluronidase, and tocilizumab and trastuzumab were used to estimate the lymphatic trunk-LN clearance $(58,63-65)$. Due to the co-formulation 
with hyaluronidase, $T_{\max }$ was over-predicted for tocilizumab and trastuzumab. The Observed $T_{\max } /$ Predicted $T_{\max }$ ratio for tocilizumab and trastuzumab was 0.58 and 0.6 , respectively. We hypothesized that the alteration of SC injection site by hyaluronidase may lead to altered SC injection site lymph flow. Therefore, lymphatic trunk-LN clearance and SC injection site lymph flow were estimated simultaneously (Table 4). After the simultaneous estimation of both the parameters, $T_{\max }$ prediction was improved for tocilizumab (Observed $T_{\max } /$ Predicted $\left.T_{\max }=0.87\right)$. Similarly, trastuzumab $T_{\max }$ prediction accuracy was also improved (Observed $T_{\max } /$ Predicted $T_{\max }=0.82$ ). The estimated SC injection site lymph flow for the co-formulation of the $\mathrm{mAb}$ and hyaluronidase was higher when compared to the original lymph flow used in the model. The estimated SC injection site lymph flow for tocilizumab was $0.04474 \mathrm{~L} / \mathrm{h}$, which was 330fold higher than the minimal PBPK model's value (Table 1). In the case of trastuzumab, the average SC injection site lymph flow was $0.002955 \mathrm{~L} / \mathrm{h}$ (22-fold higher than the original value) for healthy volunteers and HER2-positive breast cancer patients (64) (observed and model estimated PK profiles shown in Figure 6). In the case of other SC PK profile (65) (data not shown) obtained from the healthy volunteers, SC site lymph flow was 0.01307 L/h (96fold higher than the original value).

In addition to above analysis, the SC PK (tocilizumab) profiles obtained without coformulation with hyaluronidase enzyme were also used for simultaneous estimation of the SC injection site lymph flow and lymphatic trunk-LN clearance using the minimal PBPK model. This was done to demonstrate that the change in the SC site lymph flow observed previously was in fact due to coformulation of hyaluronidase and $\mathrm{mAbs}$. In the case of tocilizumab without hyaluronidase, the SC site lymph flow was $0.0009557 \mathrm{~L} / \mathrm{h}$ (only 7-fold higher than the original value). This proves that the SC injection site lymph flow was altered when hyaluronidase co-formulation strategy was used. For the SC profiles where this strategy was not used, the SC injection site lymph flow was relatively less affected.

\section{Comparison of lymphatic trunk-LN clearance with $p I$ and bioavailability of $m A b s$}

The estimated lymphatic trunk-LN clearance was compared with the $p I$ (Figure 7) and bioavailability
(Figure 8) of mAbs. The interstitial space has overall anionic charge due to cell surface of various immune cells in the LNs. The mAbs with higher $p I$ had higher values of the estimated lymphatic trunk-LN clearance. The lymphatic trunk-LN clearance increased with decrease in bioavailability (obtained from literature) of the mAbs (Figure 8). This suggests that the model accounted for the lymphatic proteolysis of mAbs after SC administration. This may indicate that the lymphatic system was an important organ for clearance of mAbs.

\section{SENSITIVITY ANALYSIS}

The sensitivity analysis showed that the $\mathrm{SC}$ injection site interstitial volume $\left(V_{S C}^{I}\right)$, SC lymph flow $\left(L_{S C}\right)$, and lymphatic capillary volume $\left(V^{L C a p}\right)$, and afferent lymph flow $\left(L_{A f f}\right)$ were responsible for changes in $C_{\max }$ and $T_{\max }$ of mAbs (Supplementary Figure 1). In the case of lymphatic trunk-LN interstitial volume $\left(V_{L Y}^{I}\right)$, increases of the volume by 50 - and 100-fold lead to alterations of $\mathrm{mAb} \mathrm{PK}$ profiles, while changes by 0.1 to 10 -fold of the original value did not alter $C_{\max }$ or $T_{\max }$. The alteration of lymphatic trunk-LN clearance $\left(C L_{L N}\right)$ and efferent lymph flow $\left(L_{E f f}\right)$ mainly lead to modification of the $C_{\max }$. In addition, changes in the thoracic duct lymph flow $\left(L_{T h o r}\right)$ and central lymphatic volume $\left(V_{L Y-C e n}\right)$ did not impact PK of mAbs. This indicates that transit through the initial lymphatic system after SC injection is the rate determining step for $\mathrm{mAb}$ absorption instead of the thoracic duct. Therefore, SC injection site volume, SC injection site lymph flow, lymphatic capillary volume, afferent lymph flow, and efferent lymph flow are important physiological parameters for absorption of mAbs. Change in the thoracic duct lymph flow and central lymphatic volume did not alter the PK of mAbs (Supplementary Figures 1). Both the $C_{\max }$ and $T_{\max }$ were sensitive to change in the SC injection site volume, SC injection site lymph flow, lymphatic capillary volume, and afferent lymph flow (Supplementary Figures 3 to 7). However, changes in the efferent lymph flow had no impact on $T_{\max }$. In addition, when the lymphatic reflection coefficient was increased; $C_{\max }$ decreased, while $T_{\max }$ increased. There was no change in the PK profile after alteration of the vascular reflection coefficient (Supplementary Figure 2). 

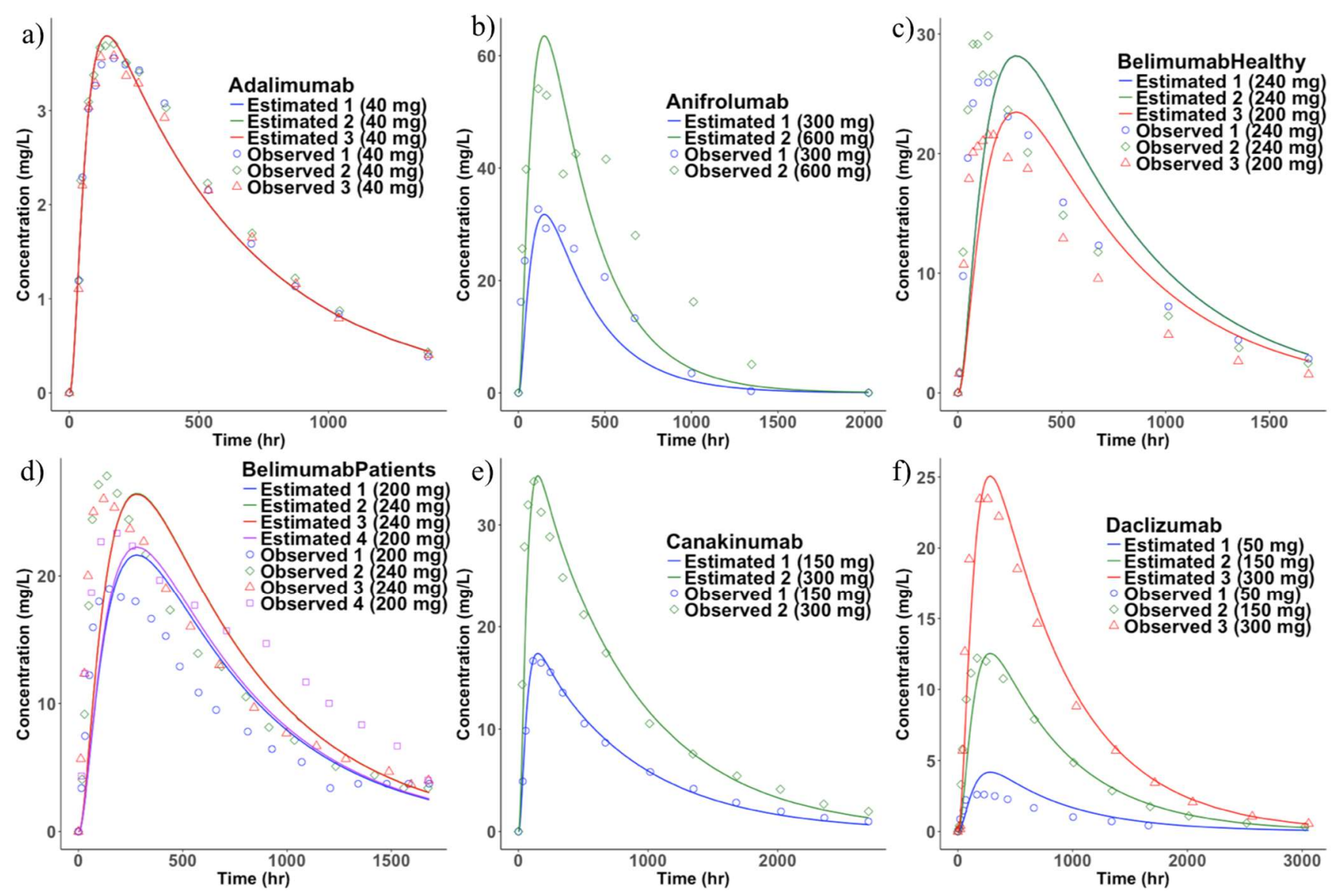

Figure 5. Observed and the model fitted SC PK profiles. a) adalimumab, b) anifrolumab, c) belimumab-Healthy, d) belimumab-patients, e) canakinumab, and f) daclizumab (Mean observed PK profiles were used for comparison with the model estimates. Observed belimumab-patient PK profile was geometric mean).

\section{Model validation}

Accuracy of the model prediction was evaluated by plotting observed and predicted values of $C_{\max }$ and $T_{\max }$ (Supplementary Figure 8). In addition, the ratio of observed and predicted $C_{\max }$ and $T_{\max }$ were plotted with the $p I$, lymphatic trunk-LN clearance, and bioavailability (Supplementary Figure 9, 10, and 11). In the case of $C_{\max }$, all predicted values were within 1.2-to 0.5 -fold of the observed literature values. The predicted $T_{\max }$ was within the range of 1.8 to 0.3 -fold of the observed values.

\section{DISCUSSION}

In this manuscript, the sequential transfer of mAbs after SC administration via the lymphatic system is described using the minimal PBPK model. The SC injection site (interstitial, endosomal, vascular), lymphatic capillaries, lymphatic trunk-LNs (interstitial and endosomal), central lymphatic system (thoracic duct and cisterna chyli) compartments were used to describe the transit of mAbs after SC administration. The rest of the body was modeled with a 2-compartment model based on the literature IV PK data. The sequential transfer was based on the known anatomy of lymphatic system (24-27). However, detailed routes of TP transfer via different LNs remain to be investigated further. Also, some individuals may have alterations in the clearance patterns, for example the clearance in the arm, shoulder and thigh may be significantly changed after radical mastoidectomy. In addition, an injection site may clear into multiple adjacent lymph basins. 

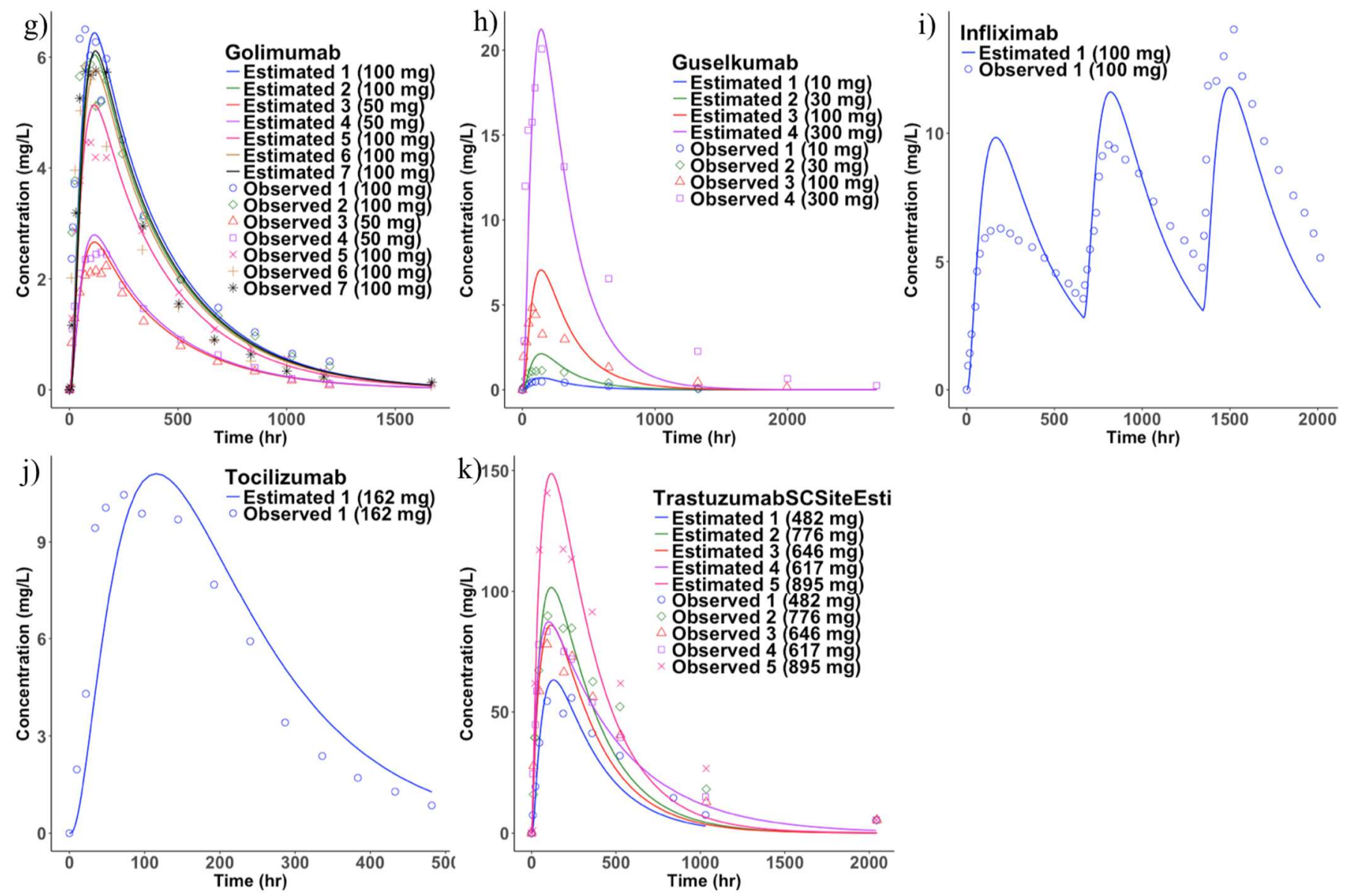

Figure 6. Observed and the model fitted SC PK profiles. g) golimumab, h) guselkumab, i) infliximab, j) tocilizumab, and k) trastuzumab (Mean observed PK profiles were used for comparison with the model estimates)

a) Lymphatic Trunk-LN Clearance vs Isoelectric point

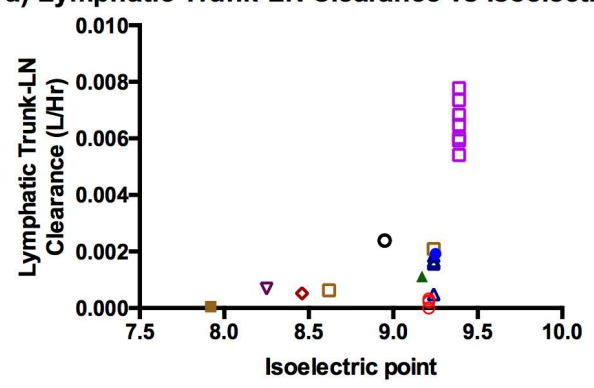

- Adalimumab

- Belimumab

- Canakinumab

ㅁ Golimumab

- Anifrolumab

- Guselkumab

口 Tocilizumab

$\Delta$ Trastuzumab

$\nabla$ Infliximab

- Daclizumab

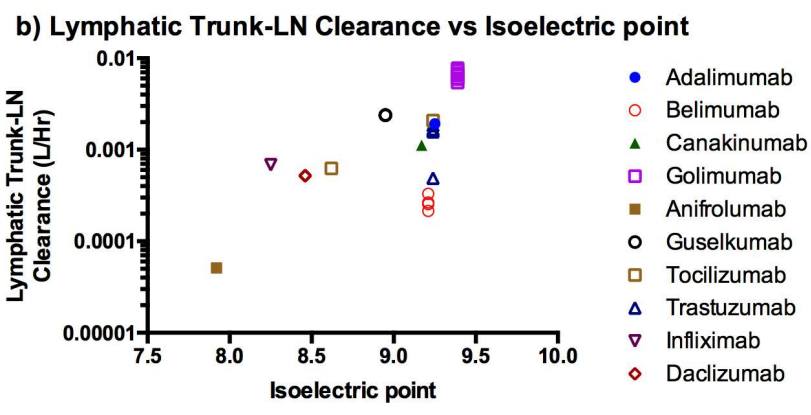

Figure 7. Correlation of the model estimated lymphatic trunk-LN clearance with the isoelectric point a) Linear scale, b) Logarithmic scale

The clearance from the interstitial space of the SC injection site was not considered in the model, because a previously reported study indicated that protein $(\mathrm{hGH})$ degradation was minimal at the SC injection site (5). In addition, simultaneous estimation of the clearance from the SC interstitial space and lymphatic trunk-LN interstitial compartment resulted in a minor contribution for the $\mathrm{SC}$ injection site proteolysis (data not shown). However, the endosomal proteolysis in the SC injection site and LNs was considered. 

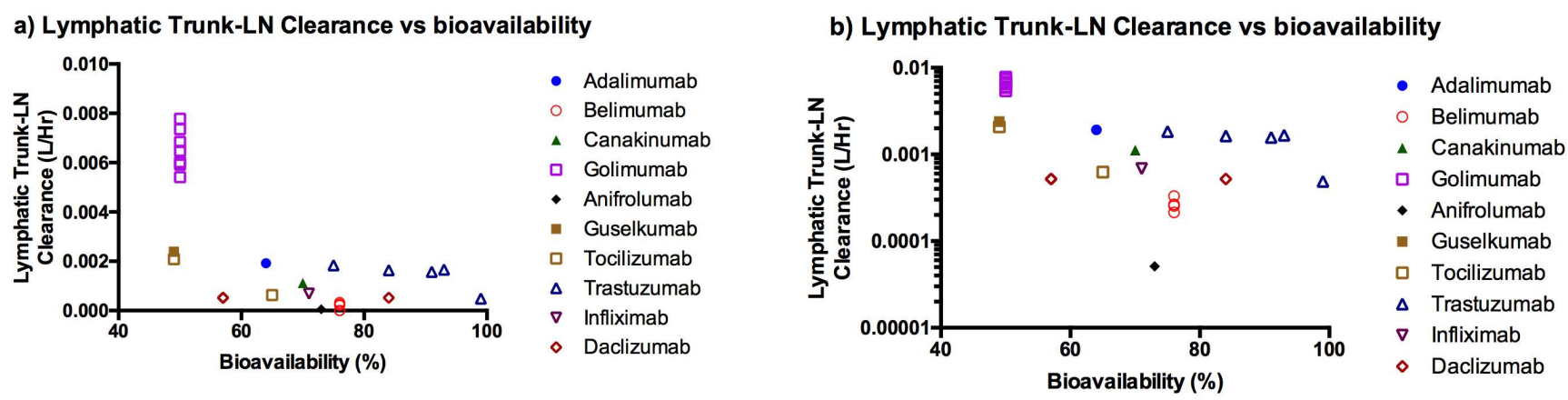

Figure 8. Correlation of the model estimated lymphatic trunk-LN clearance with the bioavailability a) Linear scale, b) Logarithmic scale (Trastuzumab: Co-formulated with hyaluronidase. Tocilizumab: Only one sample co-formulated with hyaluronidase.)

The lymphatic trunk-LN interstitial clearance was estimated using the minimal PBPK model and the literature SC PK data (Figure 4 and Table 4). The estimated clearance differed with dosing and population changes. This alteration of the estimated clearance may be due to disease condition, change in formulation, or the differences in posttranslational modifications (e.g. glycosylation). These differences were not considered in the model. The model demonstrated that the estimated lymphatic trunk-LN clearance of mAbs may correlate with the bioavailability (Figure 8). The estimated clearance increased when the bioavailability of the $\mathrm{mAb}$ decreased. This indicates efficiency of the model to account for the proteolysis of mAbs in the lymphatic system. According to the previously published reports, proteolysis was not observed after incubation of TPs with the freshly collected lymph, indicating absence of any protease enzymes in the lymph $(5,68)$. In this study, the lymphatic trunk volume (which mainly contains lymph fluid) and the LN (which mainly contains lymph node cells) volume were combined to represent the compartment responsible for proteolysis of the mAbs. The lymphatic trunk-LN compartment was mainly composed of the $\mathrm{LN}$ volume. The lymphatic trunk volume representing volume of the lymph fluid was very minor $(<7 \%)$.

Sensitivity analysis (Supplementary Figure 1) showed that the lymphatic trunk-LN interstitial space proteolysis was important to govern $C_{\max }$ of the mAbs. The degradation of mAbs in the lymphatic system was primarily due to extracellular or interstitial proteolysis. The protease enzymes secreted by the LN and other immune cells in the interstitial space may play an important role in reducing the bioavailability of mAbs. Intracellular or endosomal proteolysis of $\mathrm{mAbs}$ was negligible due to FcRn binding-mediated protection. The intracellular proteolysis of $\mathrm{mAbs}$ in the lymphatic system may be dependent on their uptake by the lymphocytes. In this model, we used endosomal uptake rate (R1) from a literature PBPK model (estimated by fitting liver data) $(3,4)$. Alteration of the endosomal uptake rate by 0.1 to 100 -fold of the original value did not change the PK of mAbs (data not shown). However, in vitro studies to calculate R1 may be useful for an accurate understanding of proteolytic processes in the SC injection site and lymphatic system. Disease conditions like inflammation may also increase proteolytic activity of the lymph. However, this remains to be further investigated. In addition, alteration of the recycling fraction of FcRn bound $\mathrm{mAb}$, dissociation constant for, dissociation constant for antibody FcRn binding, and FcRn concentration did not change PK of mAbs (data not shown).

Wang et al. (68) confirmed proteolysis of erythropoietin in the presence of rat $\mathrm{LN}$ cell suspension. The protein completely disappeared after the number of LN cells in the incubation was increased. This indicates that LNs are responsible for proteolysis of TPs. In addition, after incubation of the protein with the SC tissue homogenate, $90-95 \%$ of the parent protein remained unaffected (68). Although the authors raised doubts about loss of proteolytic activity during preparation of the SC tissue homogenate, this finding corroborates our conclusion that the SC site degradation plays a minor role in governing the bioavailability. However, in another study, insulin was reported to degrade at the $\mathrm{SC}$ injection site (69). Detailed investigation of in 
vitro proteolysis of $\mathrm{mAbs}$ in various systems must be done to arrive at more definite conclusion about the cause of reduced bioavailability after SC administration.

The PK studies in humans indicate that variation in the injection site (abdomen and thigh) do not have any impact on $C_{\max }$ and $\mathrm{AUC}_{0-\infty}$ of belimumab (44). In another clinical study, golimumab's median $T_{\max }$ after SC injection in the thigh was 1.25-fold higher than $\mathrm{SC}$ injection in the abdomen and upper arm. The $C_{\max }$ after thigh SC injection was 1.33-fold higher than SC injection in the upper arm, and the $C_{\max }-$ abdomen was 1.24-fold higher than that of the upper arm (42). This suggests that the volumes of lymphatic compartments and lymph flows may not be significantly different for each of the SC injection sites. Therefore, lymphatic volumes and flows rates for one injection site may be applied to the other. The calculations used in the model showed that the interstitial volume of the lymphatic trunk-LN was similar for various SC injection sites (upper arm, abdomen, and thigh) (Table 1).

The prediction accuracy of the model was determined by plotting observed and predicted PK parameters (Supplementary Figure 8). There was no correlation of the prediction accuracy of $T_{\max }$ or $C_{\max }$ with the $p I$ or bioavailability or the estimated lymphatic trunk-LN clearance of mAbs. This confirms that the $p I$ of mAbs did not affect the uptake by lymphatic system. Similarly, lymphatic trunk-LN clearance and bioavailability did not govern the prediction accuracy of the model.

The model also showed that for the mAbs with higher $p I$, the estimated lymphatic trunk-LN clearance was greater. The cationic proteins with higher $p I$ have a propensity to bind with the anionic cell surfaces and interstitial space (e.g. hyaluronic acid). Higher $p I$ also leads to faster clearance of mAbs (70). Similar trend was observed for the mAbs investigated in this study (Figure 7). This correlation may be used to predict the lymphatic trunk-LN clearance based on the known $p I$ of mAbs. The lymphatic clearance can be used in the minimal PBPK model to predict SC PK of the mAbs.

Sensitivity analysis of the model parameters indicate that the initial lymphatics are rate determining for absorption of mAbs via the SC route. Mainly, the SC injection site lymph flow, SC injection site volume, afferent lymph flow, efferent lymph flow, and lymphatic trunk-LN volume impacted $T_{\max }$, after their alteration by 0.1 to 100 -fold of the original value. However, thoracic duct lymph flow had no effect on $T_{\max }$ after 0.1 to 100 -fold change in its value. Therefore, alteration of thoracic lymph duct flows due to disease condition may not alter overall PK of mAbs. However, the parameters associated with the initial lymphatic system are important to govern the absorption of mAbs and change in those parameters due to the disease conditions may significantly alter the SC PK of mAbs.

It was reported earlier that the PK of mAbs is prone to high inter-subject variability. Factors like body weight, age, sex, ethnicity, disease condition, immune status are responsible for variations in the PK (71). However, more research is needed to evaluate their influence on physiological parameters related to the SC injection site and lymphatic system. The minimal PBPK model may be used for prediction of bioavailability of mAbs using in vitro lymphatic proteolysis data and to evaluate the impact of changes in lymphatic flow rates on the PK. In addition, the model may be utilized to guide in vitro experiments for mechanistic prediction of the bioavailability. This study has explained various physiological parameters related to the SC injection site and lymphatic system responsible for regulating the PK of mAbs.

\section{CONCLUSION}

The lymphatic trunk-LN clearance was estimated using the minimal PBPK model. The physiological parameters related to the SC tissue and lymphatic system were used along with the 2-compartment IV parameters to construct the minimal PBPK model for prediction of SC PK of the mAbs. The model may serve as a platform to utilize the in vitro clearance data from the SC tissue and lymphatic system to predict SC PK of mAbs. The LNs were mainly responsible for proteolysis of $\mathrm{mAbs}$ leading to their reduced bioavailability. Therefore, LN cell suspension may be used to generate inputs for the PBPK model. However, the in vitro studies were beyond the scope of this manuscript. Further, this study identified SC injection site lymph flow, afferent lymph flow, efferent lymph flow, volumes associated with the SC injection site, and lymphatic trunk-LN clearance as important parameters responsible for absorption of mAbs. The lymphatic trunk-LN clearance increased with increase in the $p I$ of mAbs. Therefore, the $p I$ of mAbs can be used to calculate the lymphatic clearance. Overall, the model 
is useful to understand disposition of mAbs after SC administration.

\section{ACKNOWLEDGEMENT}

The authors were supported by a generous grant from NIH (R01CA173292). NV was partially supported by a Higuchi Fellowship and the Department of Pharmaceutical Chemistry, The University of Kansas. We are also grateful to the J.R. and Inez Jay funds, awarded to MLF by the Higuchi Biosciences Center at The University of Kansas.

\section{REFERENCES}

1. Jackisch C, Müller V, Maintz C, Hell S, Ataseven B. Subcutaneous administration of monoclonal antibodies in oncology. Geburtshilfe Frauenheilkd. 2014;74(4):343

2. Dirks NL, Meibohm B. Population pharmacokinetics of therapeutic monoclonal antibodies. Clin Pharmacokinet. 2010;49(10):633-659

3. Zhao L, Ji P, Li Z, Roy P, Sahajwalla CG. The antibody drug absorption following subcutaneous or intramuscular administration and its mathematical description by coupling physiologically based absorption process with the conventional compartment pharmacokinetic model. J Clin Pharmacol. 2013;53(3):314-325

4. Davda JP, Jain M, Batra SK, Gwilt PR, Robinson DH. A physiologically based pharmacokinetic (PBPK) model to characterize and predict the disposition of monoclonal antibody CC49 and its single chain Fv constructs. Int Immunopharmacol. 2008;8(3):401413

5. Charman SA, Segrave AM, Edwards GA, Porter CJ. Systemic availability and lymphatic transport of human growth hormone administered by subcutaneous injection. J Pharm Sci. 2000;89(2):168177

6. Abuqayyas L, Balthasar JP. Application of PBPK modeling to predict monoclonal antibody disposition in plasma and tissues in mouse models of human colorectal cancer. J Pharmacokinet Pharmacodyn. 2012;39(6):683-710

7. Baxter LT, Zhu H, Mackensen DG, Butler WF, Jain RK. Biodistribution of monoclonal antibodies: scaleup from mouse to human using a physiologically based pharmacokinetic model. Cancer Res. 1995;55(20):4611-4622

8. Shah DK, Betts AM. Towards a platform PBPK model to characterize the plasma and tissue disposition of monoclonal antibodies in preclinical species and human. J Pharmacokinet Pharmacodyn. 2012;39(1):67-86
9. Gill KL, Gardner I, Li L, Jamei M. A bottom-up whole-body physiologically based pharmacokinetic model to mechanistically predict tissue distribution and the rate of subcutaneous absorption of therapeutic proteins. AAPS J. 2016;18(1):156-170

10. Chen X, DuBois DC, Almon RR, Jusko WJ. Interrelationships between Infliximab and rhTNF- $\alpha$ in Plasma using Minimal Physiologically-Based Pharmacokinetic (mPBPK) Models. Drug Metab Dispos. 2017;45(7):790-797

11. Elmeliegy M, Lowe P, Krzyzanski W. Simplification of complex physiologically based pharmacokinetic models of monoclonal antibodies. AAPS J. 2014;16(4):810-842

12. Li L, Gardner I, Dostalek M, Jamei M. Simulation of Monoclonal Antibody Pharmacokinetics in HumansUsing a Minimal Physiologically Based Model. AAPS J. 2014;16(5):1097-1109

13. Sager JE, Yu J, Raguenau-Majlessi I, Isoherranen N. Physiologically based pharmacokinetic (PBPK) modeling and simulation approaches: a systematic review of published models, applications and model verification. Drug Metab Dispos. 2015;43:1823-1837

14. Wong H, Chow TW. Physiologically based pharmacokinetic modeling of therapeutic proteins. J Pharm Sci. 2017;106(9):2270-2275

15. Rohatgi A. WebPlotDigitizer, Web based tool to extract data from plots, images, and maps. 2018 Accessed on May 09, 2018. Available from: https://automeris.io/WebPlotDigitizer/.

16. Kuo I, Akpa BS. Validity of the Lipid Sink as a Mechanism for the Reversal of Local Anesthetic Systemic ToxicityA Physiologically Based Pharmacokinetic Model Study. Anesthesiology: The Journal of the American Society of Anesthesiologists. 2013;118(6):1350-1361

17. Garg A, Balthasar JP. Physiologically-based pharmacokinetic (PBPK) model to predict IgG tissue kinetics in wild-type and FcRn-knockout mice. J Pharmacokinet Pharmacodyn. 2007;34(5):687-709

18. Mellor R, Stanton A, Azarbod P, Sherman M, Levick J, Mortimer P. Enhanced cutaneous lymphatic network in the forearms of women with postmastectomy oedema. J Vasc Res. 2000;37(6):501-512

19. Nathanson SD, Nelson L, Karvelis KC. Rates of flow of technetium 99m-labeled human serum albumin from peripheral injection sites to sentinel lymph nodes. Ann Surg Oncol. 1996;3(4):329-335

20. Margaris K, Black RA. Modelling the lymphatic system: challenges and opportunities. J R Soc Interface. 2012;9(69):601-612

21. Fischer M, Franzeck UK, Herrig I, Costanzo U, Wen S, Schiesser M, Hoffmann U, Bollinger A. Flow velocity of single lymphatic capillaries in human skin. Am J Physiol Heart Circ Physiol. 1996;270(1):H358-H363 
22. Fujiwara M, Sawada M, Kasuya A, Matsushita Y, Yamada M, Fukamizu H, Magata Y, Tokura Y, Sakahara H. Measurement of cutaneous lymphatic flow rates in patients with skin cancer: area extraction method. J Dermatol. 2014;41(6):498-504

23. Quin J, Shannon A. The influence of the lymph node on the protein concentration of efferent lymph leaving the node. J Physiol. 1977;264(2):307-321

24. Lymphatics of the Upper Limb. Department of Neurobiology and Developmental Sciences, University of Arkansas for Medical Sciences. Accessed on April 14, 2018. Available from: http://anatomy.uams.edu/lymph upperlimb.html.

25. Bontumasi N, Jacobson JA, Caoili E, Brandon C, Kim SM, Jamadar D. Inguinal lymph nodes: size, number, and other characteristics in asymptomatic patients by CT. Surg Radiol Anat. 2014;36(10):10511055

26. Usovich A, Borziak E. Variants in the number and size and the topography of the lumbar lymph nodes in the regional of the liver in the human adult. Arkh Anat Gistol Ehmbriol. 1982;83(7):29-33

27. Ying M, Pang B. Three-dimensional ultrasound measurement of cervical lymph node volume. $\mathrm{Br} \mathrm{J}$ Radiol. 2009;82(980):617-625

28. Corlier F, Rivals I, Lagarde J, Hamelin L, Corne H, Dauphinot L, Ando K, Cossec J, Fontaine G, Dorothée G. Modifications of the endosomal compartment in peripheral blood mononuclear cells and fibroblasts from Alzheimer's disease patients. Transl Psychiatry. 2015;5(7):e595

29. Sikorski E, Gerberick G, Ryan C, Miller C, Ridder G. Phenotypic analysis of lymphocyte subpopulations in lymph nodes draining the ear following exposure to contact allergens and irritants. Fundam Appl Toxicol. 1996;34(1):25-35

30. Skandalakis JE, Skandalakis LJ, Skandalakis PN. Anatomy of the lymphatics. Surg Oncol Clin N Am. 2007;16(1):1-16

31. Lymphatics of the Lower Limb. Department of Neurobiology and Developmental Sciences, University of Arkansas for Medical Sciences. Accessed on April 14, 2018. Available from: http://anatomy.uams.edu/lymph_lowerlimb.html.

32. Lymphatics of the Abdomen. Department of Neurobiology and Developmental Sciences, University of Arkansas for Medical Sciences. Accessed on April 14, 2018. Available from: http://anatomy.uams.edu/lymph_abdomen.html.

33. Giragossian C, Vage C, Li J, Pelletier K, PichéNicholas N, Rajadhyaksha M, Liras J, Logan A, Calle RA, Weng Y. Mechanistic Investigation of the Preclinical Pharmacokinetics and Interspecies Scaling of PF-05231023, a Fibroblast Growth Factor 21-Antibody Protein Conjugate. Drug Metab Dispos. 2015;43(6):803-811
34. Dumont AE, Mulholland JH. Flow rate and composition of thoracic-duct lymph in patients with cirrhosis. N Engl J Med. 1960;263(10):471-474

35. Zhou J, Johnson JE, Ghetie V, Ober RJ, Ward ES. Generation of mutated variants of the human form of the MHC class I-related receptor, FcRn, with increased affinity for mouse immunoglobulin G. J Mol Biol. 2003;332(4):901-913

36. Ferl GZ, Wu AM, DiStefano JJ. A predictive model of therapeutic monoclonal antibody dynamics and regulation by the neonatal $\mathrm{Fc}$ receptor $(\mathrm{FcRn})$. Ann Biomed Eng. 2005;33(11):1640-1652

37. Center for drug evaluation and research, guselkumab application 761061Orig1s000 2018 Accessed on April 13, 2018. Available from: https://www.accessdata.fda.gov/drugsatfda_docs/nd a/2017/761061 Orig1s000OtherR.pdf.

38. Doyle Keith, Halo Maria, Harding Emma R, Lewis Peter, Uden Mark, Damian Valeriu, Xuan H. Antibody variants. In.; 2017.

39. Hillson J, Mant T, Rosano M, Huntenburg C, AlaiSafar M, Darne S, Palmer D, Pavlova BG, Doralt J, Reeve R. Pharmacokinetic equivalence, comparable safety, and immunogenicity of an adalimumab biosimilar product (M923) to Humira in healthy subjects. Pharmacol Res Perspect. 2018;6(1)

40. Chakraborty A, Tannenbaum S, Rordorf C, Lowe PJ, Floch D, Gram H, Roy S. Pharmacokinetic and pharmacodynamic properties of canakinumab, a human anti-interleukin-1 $\beta$ monoclonal antibody. Clin Pharmacokinet. 2012;51(6):e1-e18

41. Ling J, Lyn S, Xu Z, Achira M, Bouman-Thio E, Shishido A, Ford J, Shankar G, Wagner C, Kim KT. Lack of racial differences in the pharmacokinetics of subcutaneous golimumab in healthy Japanese and Caucasian male subjects. J Clin Pharmacol. 2010;50(7):792-802

42. Xu Z, Wang Q, Zhuang Y, Frederick B, Yan H, Bouman-Thio E, Marini JC, Keen M, Snead D, Davis HM. Subcutaneous bioavailability of golimumab at 3 different injection sites in healthy subjects. J Clin Pharmacol. 2010;50(3):276-284

43. Yapa SWS, Roth D, Gordon D, Struemper H. Comparison of intravenous and subcutaneous exposure supporting dose selection of subcutaneous belimumab systemic lupus erythematosus Phase 3 program. Lupus. 2016;25(13):1448-1455

44. Cai WW, Fiscella M, Chen C, Zhong ZJ, Freimuth WW, Subich DC. Bioavailability, pharmacokinetics, and safety of belimumab administered subcutaneously in healthy subjects. Clin Pharmacol Drug Dev. 2013;2(4):349-357

45. Tummala R, Rouse T, Berglind A, Santiago L. Safety, tolerability, and pharmacokinetics of subcutaneous and intravenous anifrolumab in healthy volunteers. In.ACR/ARHP Annual Meeting: BMJ Publishing Group Ltd; 2017. 
46. Zhuang Y, Calderon C, Marciniak SJ, Bouman-Thio E, Szapary P, Yang T-Y, Schantz A, Davis HM, Zhou $\mathrm{H}, \mathrm{Xu}$ Z. First-in-human study to assess guselkumab (anti-IL-23 mAb) pharmacokinetics/safety in healthy subjects and patients with moderate-to-severe psoriasis. Eur J Clin Pharmacol. 2016;72(11):13031310

47. Product monograph for Tremfya (guselkumab). Janssen Inc. . Accessed on April 16, 2018. Available from:

http://www.janssen.com/canada/sites/www_janssen_ com_canada/files/prod_files/live/tremfya_cpm.pdf.

48. Infliximab DrugBank. 2018 Accessed on May 17, 2018. Available from: https://www.drugbank.ca/drugs/DB00065.

49. Daclizumab DrugBank. 2018 Accessed on May 17, $2018 . \quad$ Available from: https://www.drugbank.ca/drugs/DB00111.

50. Miao S, Fan L, Zhao L, Ding D, Liu X, Wang H, Tan W-S. Physicochemical and Biological Characterization of the Proposed Biosimilar Tocilizumab. Biomed Res Int. 2017;2017

51. International Nonproprietary Names for Pharmaceutical Substances (INN), WHO Drug Information, Vol. 28, No. 1, 2014 (INN List 71). Accessed on May 25, 2018. Available from: http://www.who.int/medicines/publications/druginfo rmation/innlists/RL71.pdf.

52. Gasteiger E, Hoogland C, Gattiker A, Wilkins MR, Appel RD, Bairoch A. Protein identification and analysis tools on the ExPASy server. In. The proteomics protocols handbook: Springer; 2005. p. 571-607.

53. Weisman MH, Moreland LW, Furst DE, Weinblatt ME, Keystone EC, Paulus HE, Teoh LS, Velagapudi RB, Noertersheuser PA, Granneman GR. Efficacy, pharmacokinetic, and safety assessment of adalimumab, a fully human anti-tumor necrosis factor-alpha monoclonal antibody, in adults with rheumatoid arthritis receiving concomitant methotrexate: a pilot study. Clin Ther. 2003;25(6):1700-1721

54. Goldberg A, Geppert T, Schiopu E, Frech T, Hsu V, Simms RW, Peng SL, Yao Y, Elgeioushi N, Chang L. Dose-escalation of human anti-interferon- $\alpha$ receptor monoclonal antibody MEDI-546 in subjects with systemic sclerosis: a phase 1 , multicenter, open label study. Arthritis Res Ther. 2014;16(1):R57

55. Othman AA, Tran JQ, Tang MT, Dutta S. Population pharmacokinetics of daclizumab high-yield process in healthy volunteers: integrated analysis of intravenous and subcutaneous, single-and multipledose administration. Clin Pharmacokinet. 2014;53(10):907-918

56. Zhou H, Jang H, Fleischmann RM, Bouman-Thio E, $\mathrm{Xu} \mathrm{Z,} \mathrm{Marini} \mathrm{JC,} \mathrm{Pendley} \mathrm{C,} \mathrm{Jiao} \mathrm{Q,} \mathrm{Shankar} \mathrm{G,}$ Marciniak SJ. Pharmacokinetics and safety of golimumab, a fully human anti-TNF- $\alpha$ monoclonal antibody, in subjects with rheumatoid arthritis. J Clin Pharmacol. 2007;47(3):383-396

57. Palaparthy R, Udata C, Hua SY, Yin D, Cai C-H, Salts S, Rehman MI, McClellan J, Meng X. A randomized study comparing the pharmacokinetics of the potential biosimilar PF-06438179/GP1111 with

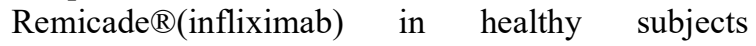
(REFLECTIONS B537-01). Expert Rev Clin Immunol. 2018;14(4):329-336

58. Zhang X, Georgy A, Rowell L. Pharmacokinetics and pharmacodynamics of tocilizumab, a humanized antiinterleukin-6 receptor monoclonal antibody, following single-dose administration by subcutaneous and intravenous routes to healthy subjects. Int J Clin Pharmacol Ther. 2013;51(6):443455

59. Morita J, Tanaka M, Nomoto M, Matsuki S, Tsuru T, Matsuguma K, Shiramoto M. Pharmacokinetic bioequivalence, safety, and immunogenicity of DMB-3111, a trastuzumab biosimilar, and trastuzumab in healthy Japanese adult males: results of a randomized trial. BioDrugs. 2016;30(1):17-25

60. Pivot X, Deslypere JP, Park LS, Kim MJ, Lee W, Lee J. A Randomized Phase I Study Comparing the Pharmacokinetics of HD201, a Trastuzumab Biosimilar, With European Union-sourced Herceptin. Clin Ther. 2018;40(3):396-405. e394

61. Westhovens R, Houssiau F, Joly J, Everitt DE, Zhu Y, Sisco D, Van Hartingsveldt B, Mascelli MA, Graham MA, Durez P. A phase I study assessing the safety, clinical response, and pharmacokinetics of an experimental infliximab formulation for subcutaneous or intramuscular administration in patients with rheumatoid arthritis. J Rheumatol. 2006;33(5):847-853

62. Zhu Y, Pendley C, Sisco D, Westhovens R, Durez P, Bouman-Thio E, Hartingsveldt B, Everitt D, Graham M. Pharmacokinetics and pharmacodynamics of infliximab, an anti-tumor necrosis factor-alpha monoclonal antibody, following single subcutaneous administrations in rheumatoid arthritis patients. Clin Pharmacol Ther. 2005;77(2)

63. Morcos PN, Zhang X, McIntyre C, Bittner B, Rowell L, Hussain Z. Pharmacokinetics and pharmacodynamics of single subcutaneous doses of tocilizumab administered with or without $\mathrm{rHuPH} 20$. Int J Clin Pharmacol Ther. 2013;51(7):537-548

64. Wynne C, Harvey V, Schwabe C, Waaka D, McIntyre C, Bittner B. Comparison of Subcutaneous and Intravenous Administration of Trastuzumab: A Phase $\mathrm{I} / \mathrm{Ib}$ Trial in Healthy Male Volunteers and Patients With HER2-Positive Breast Cancer. J Clin Pharmacol. 2013;53(2):192-201

65. Wynne CJ, Ellis-Pegler RB, Waaka DS, Schwabe C, Lehle M, Heinzmann D, Mangat R, Li C, Dick AE, Cranshaw NA. Comparative pharmacokinetics of 
subcutaneous trastuzumab administered via handheld syringe or proprietary single-use injection device in healthy males. Cancer Chemother Pharmacol. 2013;72(5):1079-1087

66. Richter WF, Jacobsen B. Subcutaneous Absorption of Biotherapeutics: Knowns and Unknowns. Drug Metab Dispos. 2014;42(11):1881-1889

67. Liu S, Xie B, Wei W, Hui M, Su Z. Design and preparation of chimeric hyaluronidase as a chaperone for the subcutaneous administration of biopharmaceuticals. Biochem Eng J. 2016;112:32-41

68. Wang W, Chen N, Shen X, Cunningham P, Fauty S, Michel K, Wang B, Hong X, Adreani C, Nunes CN. Lymphatic transport and catabolism of therapeutic proteins after subcutaneous administration to rats and dogs. Drug Metab Dispos. 2012;40(5):952-962

69. Okumura K, Komada F, Hori R. Fate of porcine and human insulin at the subcutaneous injection site. I. degradation and absorption of insulins in the rat. $\mathbf{J}$ Pharmacobiodyn. 1985;8(1):25-32

70. Bumbaca D, Boswell CA, Fielder PJ, Khawli LA. Physiochemical and biochemical factors influencing the pharmacokinetics of antibody therapeutics. AAPS J. 2012;14(3):554-558

71. Gill KL, Machavaram KK, Rose RH, Chetty M. Potential sources of inter-subject variability in monoclonal antibody pharmacokinetics. Clin Pharmacokinet. 2016;55(7):789-805 


\section{APPENDIX}

In addition to the data figures in the Supplementary materials, all raw digitalized data and the SimBiology (Matlab 2017a) model file used in this study are archived and available free of charge at the University of Kansas Scholar Works Repository (https://kuscholarworks.ku.edu/handle/1808/26648)

\section{Model equations}

$$
\begin{aligned}
& V_{S C}^{I}\left(\frac{d C_{S C}^{I}}{d t}\right)=\left(\left(1-\sigma_{V}\right) \times L_{S C} \times C_{S C}^{V}\right)-\left(R 1 \times C_{S C}^{I}\right)+\left((1-F R) \times R 2 \times\left(1-f_{u S C}\right) \times C_{S C}^{E}\right) \\
& -\left(\left(1-\sigma_{L}\right) \times L_{S C} \times C_{S C}^{I}\right) \\
& V_{S C}^{V}\left(\frac{d C_{S C}^{V}}{d t}\right)=-\left(\left(1-\sigma_{V}\right) \times L_{S C} \times C_{S C}^{V}\right)-\left(\left(Q_{S C}-L_{S C}\right) \times C_{S C}^{V}\right)+\left(F R \times R 2 \times\left(1-f_{u S C}\right) \times C_{S C}^{E}\right) \\
& -\left(R 1 \times C_{S C}^{V}\right)+\left(Q_{S C} \times C_{C e n}\right) \\
& V_{S C}^{E}\left(\frac{d C_{S C}^{E}}{d t}\right)=\left(R 1 \times C_{S C}^{I}\right)-\left(F R \times R 2 \times\left(1-f_{u S C}\right) \times C_{S C}^{E}\right)-\left((1-F R) \times R 2 \times\left(1-f_{u S C}\right) \times C_{S C}^{E}\right) \\
& +\left(R 1 \times C_{S C}^{V}\right)-\left(\left(1-f_{u S C}\right) \times C L_{E n} \quad \times C_{S C}^{E}\right) \\
& V^{L C a p}\left(\frac{d C^{L C a p}}{d t}\right)=\left(\left(1-\sigma_{L}\right) \times L_{S C} \times C^{L C a p}\right)-\left(L_{A f f} \times C^{L C a p}\right) \\
& V_{L N}^{I}\left(\frac{d C_{L N}^{I}}{d t}\right)=\left(L_{A f f} \times C_{L N}^{C a p}\right)-\left(L_{E f f} \times C_{L N}^{I}\right)-\left(C L_{L N} \times C_{L N}^{I}\right)-\left(R 1 \times C_{L N}^{I}\right) \\
& +\left((1-F R) \times R 2 \times\left(1-f_{u L N}\right) \times C_{L N}^{E}\right) \\
& V_{L N}^{E}\left(\frac{d C_{L N}^{E}}{d t}\right)=\left(R 1 \times C_{L N}^{I}\right)-\left((1-F R) \times R 2 \times\left(1-f_{u L N}\right) \times C_{L N}^{E}\right)-\left(\left(1-f_{u L N}\right) \times C L_{E n d o-L N} \times C_{L N}^{E}\right) \\
& V_{L N-C e n}\left(\frac{d C_{L N-C}}{d t}\right)=-\left(L_{T h o r} \times C_{L N-C}\right)+\left(L_{E f f} \times C_{L N}^{I}\right) \\
& V_{C e n}\left(\frac{d C_{C e n}}{d t}\right)=\left(L_{T h o r} \times C_{L N-C}\right)+\left(\left(Q_{S C}-L_{S C}\right) \times C_{S C}^{V}\right)-\left(C L_{C e n} \times C_{C e n}\right)-\left(K_{12} \times C_{C e n}\right)+\left(K_{21} \times C_{P e r}\right) \\
& -\left(Q_{S C} \times C_{C e n}\right) \\
& V_{\text {Per }}\left(\frac{d C_{P e r}}{d t}\right)=\left(K_{12} \times C_{C e n}\right)-\left(K_{21} \times C_{P e r}\right)
\end{aligned}
$$




$$
\begin{aligned}
& f_{u S C}=1-\left(\frac{1}{2 \times\left(C_{\text {Endo }}+C_{S C}^{E}\right)}\right) \\
& \times\left(\left(K_{d}+n P t+C_{E n d o}+C_{S C}^{E}\right)\right. \\
& \left.-\left(\sqrt{\left(K d+n P t+C_{E n d o}+C_{S C}^{E}\right)^{2}-\left(4 \times\left(C_{E n d o}+C_{S C}^{E}\right) \times n P t\right)}\right)\right) \\
& f_{u L N}=1-\left(\frac{1}{2 \times\left(C_{\text {Endo }}+C_{L N}^{E}\right)}\right) \\
& \times\left(\left(K_{d}+n P t+C_{E n d o}+C_{L N}^{E}\right)\right. \\
& \left.-\left(\sqrt{\left(K d+n P t+C_{E n d o}+C_{L N}^{E}\right)^{2}-\left(4 \times\left(C_{E n d o}+C_{L N}^{E}\right) \times n P t\right)}\right)\right)
\end{aligned}
$$

\section{GLOSSARY}

\section{Parameter}

Definition

$\begin{array}{cl}C_{S C}^{V} & \text { Concentration of mAb in the vascular space of SC injection site } \\ C_{S C}^{I} & \text { Concentration of } \mathrm{mAb} \text { in the interstitial space of SC injection site } \\ C_{S C}^{E} & \text { Concentration of } \mathrm{mAb} \text { in the endosomal space of SC injection site } \\ C^{L C a p} & \text { Concentration of } \mathrm{mAb} \text { in the lymphatic capillary compartment } \\ C_{L N}^{I} & \text { Concentration of mAb in the interstitial space of lymphatic trunk-LNs } \\ C_{L N}^{E} & \text { Concentration of mAb in the endosomal space of lymphatic trunk-LNs } \\ C_{L Y-C e n} & \text { Concentration of mAb in the central lymphatic system } \\ C_{C e n} & \text { Concentration of mAb in the central compartment } \\ C_{P e r} & \text { Concentration of mAb in the peripheral compartment } \\ V_{S C}^{I} & \text { SC injection site interstitial volume } \\ V_{S C}^{V} & \text { SC injection site vascular volume } \\ V_{S C}^{E} & \text { SC injection site endosomal volume } \\ V^{L C a p} & \text { Volume of the lymphatic capillaries } \\ V_{L N}^{I} & \text { Combined interstitial volume of lymphatic trunk-LNs after SC injection in thigh } \\ V_{L N}^{E} & \text { Combined endosomal volume of all LNs to which the mAb is exposed after SC } \\ V_{L Y-C e n} & \text { injection in thigh } \\ V_{C e n} & \text { Volume of central lymphatic system } \\ V_{P e r} & \text { Volume of the central compartment } \\ L_{S C} & \text { Lymph flow at the SC injection site } \\ L_{A f f} & \text { Lymph flow afferent to LNs } \\ L_{E f f} & \text { Lymph flow efferent to LNs } \\ L_{T h o r} & \text { Thoracic duct lymph flow } \\ Q_{S C} & \text { Blood flow at the SC injection site } \\ \sigma_{L} & \text { Lymphatic reflection coefficient }\end{array}$




\begin{tabular}{cl}
\hline$\sigma_{V}$ & Vascular reflection coefficient \\
$C L_{L N}$ & Clearance of mAb in the lymphatic trunk-LN interstitial compartment \\
$C L_{E n d o-S C}$ & Endosomal clearance of $\mathrm{mAb}$ in the $\mathrm{SC}$ injection site \\
$C L_{E n d o-L N}$ & Endosomal clearance of mAb in LNs \\
$C L_{C e n}$ & Clearance of mAb from the central compartment \\
$K_{12}$ & Transfer rate constant from the central compartment to the peripheral compartment \\
$K_{21}$ & Transfer rate constant from the peripheral compartment to the central compartment \\
$f_{u S C}$ & Unbound fraction of mAb in SC tissue \\
$f_{u L N}$ & Unbound fraction of mAb in lymphatic trunk and LNs \\
$C_{E n d o}$ & Concentration of endogenous mAb in endosomal compartment \\
$R 1$ & Endosomal uptake rate of antibody \\
$R 2$ & Endosomal return rate of antibody \\
$F R$ & Recycling fraction of FcRn bound mAb \\
$K d$ & Dissociation constant for antibody FcRn binding \\
$n P t$ & FcRn concentration in SC tissue or $L N$ \\
\hline
\end{tabular}

